\title{
Context matters: Community social cohesion and health behaviors in two South African areas
}

\author{
Sheri A. Lippman ${ }^{\mathrm{a}, \mathrm{b}, *}$, Hannah H. Leslie ${ }^{\mathrm{c}, \mathrm{d}}$, Torsten B. Neilands ${ }^{\mathrm{a}}$, Rhian Twine ${ }^{\mathrm{b}}$, \\ Jessica S. Grignon ${ }^{\mathrm{e}, \mathrm{f}}$, Catherine MacPhail ${ }^{\mathrm{b}, \mathrm{g}, \mathrm{h}}$, Jessica Morris ${ }^{\mathrm{a}}$, Dumisani Rebombo ${ }^{\mathrm{i}}$, \\ Malebo Sesane ${ }^{\mathrm{f}}$, Alison M. El Ayadi ${ }^{\mathrm{j}}$, Audrey Pettifor ${ }^{\mathrm{b}, \mathrm{k}}$, Kathleen Kahn ${ }^{\mathrm{b}}$ \\ a University of California San Francisco, Center for AIDS Prevention Studies, Department of Medicine, San Francisco, CA, USA \\ b MRC/Wits Rural Public Health and Health Transitions Research Unit (Agincourt), School of Public Health, Faculty of Health Sciences, University of the \\ Witwatersrand, Johannesburg, South Africa \\ ${ }^{\mathrm{c}}$ University of California, Berkeley, Division of Epidemiology, School of Public Health, Berkeley, CA, USA \\ ${ }^{\mathrm{d}}$ Harvard T. H. Chan School of Public Health, Department of Global Health and Population, Boston, MA, USA \\ e University of Washington, Department of Global Health, Seattle, WA, USA \\ ${ }^{\mathrm{f}}$ International Training and Education Center for Health (I-TECH) South Africa, Pretoria, Republic of South Africa \\ ${ }^{\mathrm{g}}$ School of Health, University of New England, Armidale, NSW, Australia \\ ${ }^{\text {h }}$ Wits Reproductive Health and HIV Institute (WRHI), School of Clinical Medicine, Faculty of Health Sciences, University of the Witwatersrand, \\ Johannesburg, South Africa \\ ${ }^{\mathrm{i}}$ Sonke Gender Justice, Cape Town, South Africa \\ ${ }^{\mathrm{j}}$ Bixby Center for Global Reproductive Health, Department of Obstetrics, Gynecology and Reproductive Sciences, University of California, San Francisco, \\ USA \\ ${ }^{\mathrm{k}}$ University of North Carolina at Chapel Hill, Gillings School of Global Public Health, Chapel Hill, NC, USA
}

\section{A R T I C L E I N F O}

Keywords:

Social cohesion

South Africa

Alcohol

HIV testing

Health behavior

Sexual behavior

\begin{abstract}
A B S T R A C T
Background: Understanding how social contexts shape HIV risk will facilitate development of effective prevention responses. Social cohesion, the trust and connectedness experienced in communities, has been associated with improved sexual health and HIV-related outcomes, but little research has been conducted in high prevalence settings.

Methods: We conducted population-based surveys with adults 18-49 in high HIV prevalence districts in Mpumalanga $(n=2057)$ and North West Province $(n=1044)$, South Africa. Community social cohesion scores were calculated among the 70 clusters. We used multilevel logistic regression stratified by gender to assess individual- and group-level associations between social cohesion and HIV-related behaviors: recent HIV testing, heavy alcohol use, and concurrent sexual partnerships.

Results: Group-level cohesion was protective in Mpumalanga, where perceived social cohesion was higher. For each unit increase in group cohesion, the odds of heavy drinking among men were reduced by $40 \%$ (95\% CI 0.25 , $0.65)$; the odds of women reporting concurrent sexual partnerships were reduced by $45 \%(95 \% \mathrm{CI} 0.19,1.04 ; \mathrm{p}=$ 0.06 ); and the odds of reporting recent HIV testing were 1.6 and 1.9 times higher in men and women, respectively.

Conclusions: We identified potential health benefits of cohesion across three HIV-related health behaviors in one region with higher overall evidence of group cohesion. There may be a minimum level of cohesion required to yield positive health effects.
\end{abstract}

\section{Introduction}

Momentum around understanding the social determinants of health has increased in Western countries over the past three decades, with growing evidence that the social environment shapes health and health behaviors (Bronfenbrenner, 1979; Cassel, 1976; Kaplan et al., 2000; Krieger, 2001; Berkman and Kawachi, 2000). Among social contextual factors most commonly studied at a community level, social cohesion, or the shared trust, connectedness, or unity experienced by members of a residential area or social group (Sampson, 2003;

\footnotetext{
* Correspondence to: 550 16th Street, 3rd Floor, San Francisco, CA 94158-2549, USA

E-mail address: sheri.lippman@ucsf.edu (S.A. Lippman).
} 
Sampson et al., 1997; Kawachi and Berkman, 2000), has been associated with various healthy behaviors and improved health outcomes in multiple contexts. For example, seminal research in Chicago found higher levels of neighborhood collective efficacy (social trust and expectations of reciprocity or social control) correlated with lower rates of violent crime (Sampson et al., 1997). At the state level, increased membership in social organizations, or civic engagement, a construct related to social cohesion, has been associated with decreased all-cause mortality in the U.S. (Kawachi et al., 1997). More recent studies have also demonstrated a protective association between social cohesion and civic engagement with both early sexual debut and rates of sexually transmitted infections (STI) in the U.S. (Ellen et al., 2004; Holtgrave and Crosby, 2003; Jennings et al., 2014; Youngblade et al., 2006).

While evidence for the link between community social connectedness and trust and improved health outcomes is gaining traction in the U.S. context, there has been less research on these associations in lower income countries. In sub-Saharan Africa, where the HIV epidemic continues to have a strong impact on population health, few researchers have examined the impact of community social cohesion or related measures of community connectedness on HIV and HIV-related risk behaviors. Related research in sub-Saharan Africa has largely operationalized social cohesion at the individual level, as an individual's perceived level of social cohesion in his/her community or an individual's reported membership and involvement in groups. At the individual level, some evidence from African countries indicates social cohesion and civic engagement play a protective role on sexual health, increased condom use, decreased intimate partner violence, and delayed sexual debut, although not all associations have been protective (Gregson et al., 2011; Burgard and Lee-Rife, 2009; Pronyk et al., 2006; Campbell et al,. 2002).

After decades of HIV prevention and care programming focused almost entirely on individual behavior change in Africa, there is a growing call to understand how social environments shape HIV acquisition to inform critically needed improvements to HIV prevention programming, particularly in addressing modifiable social factors (Underwood et al., 2014; Poundstone et al., 2004; Fritz et al., 2010; Campbell et al., 2005; Pronyk et al., 2008a). We sought to understand the relationship between community social cohesion and behaviors associated with HIV acquisition in South Africa using data from two population-based surveys in high HIV prevalence rural districts to examine varied experiences of social cohesion and sexual risk behaviors. Specifically, we assess the association between a community-level measure of social cohesion and recent HIV testing, heavy alcohol use, and concurrent sexual partnerships.

\section{Methods}

\subsection{Setting and study design}

Data for this study came from two separate population-based HIV prevention and care research initiatives in rural and peri-urban areas of South Africa - one in North West and the other in Mpumalanga Province. Studies included similar survey data collection protocols and measures.

Data from the North West Province were collected from JanuaryMarch 2014, in Lekwa-Teemane and Greater Taung sub-Districts within Dr. Ruth Segomotsi Mompati (RSM) District. RSM is comprised of both rural and peri-urban areas, with an economy centered on beef production and agriculture. The study area includes approximately 230,000 people, the majority of whom speak Setswana. Adult HIV prevalence in the North West Province is estimated at 20.3\% (Shisana et al., 2014). Twenty-three enumeration areas (EAs) in each sub-district were selected proportionate to size based on 2011 census data (sampling frame provided by Statistics South Africa). All dwelling units (DU) in selected EAs were enumerated prior to data collection. Up to 36 inhabited DUs were then randomly selected from each
EA (1561 DUs in total) for inclusion in the sample. One adult (18-49 years) was randomly selected per DU for participation. Data collection has been described in detail elsewhere (Lippman et al., 2016a).

Data from Mpumalanga Province were collected between JulySeptember 2014, in a largely rural area of the Bushbuckridge subdistrict, within Ehlanzeni district. Remittances from migrant laborers in the nearby mining, agriculture, and tourism industries are the mainstays of the local economy. The province has the second highest HIV prevalence nationally, estimated at $21.8 \%$ among adults of reproductive age (Shisana et al., 2014). The study area is a health and socio-demographic surveillance site (Agincourt HDSS) run by the Medical Research Council/Wits University Rural Public Health and Health Transitions Research Unit. At the time the survey was conducted, just over 113,000 residents were living in 28 enumerated villages, most of whom speak XiTsonga (Shangaan) (Kahn et al., 2012). The sampling frame consisted of all HDSS households with a resident aged 18-49 in 27 villages (one small village was excluded). Random selection in each village resulted in 3456 total households for inclusion.

Selection criteria required an age range of 18-49 years, ability to provide informed consent, and household residence. In North West residency was defined as sleeping in the DU an average of four or more nights per week and in Mpumalanga residency comprised having spent at least nine of the past twelve months in the area.

\subsection{Data collection}

Fieldworkers located participants, confirmed eligibility, obtained written informed consent, and conducted a survey using computerassisted personal interviewing (CAPI) at the participant's home, in the participant's language of choice [English, Setswana, or XiTsonga]. The surveys included questions on demographic characteristics, HIV testing history, health services utilization, sexual behavior, alcohol consumption, and community social factors, including community cohesion. In the North West, participants were compensated with a mobile phone airtime voucher worth approximately five US dollars. In Mpumalanga, no compensation was offered, consistent with research unit policies. Additionally, in the North West, participants were offered HIV rapid testing at the time of the survey; testing was not an inclusion criterion for the survey.

All procedures were approved by the Committee for Human Research at the University of California, San Francisco (UCSF). Procedures for the North West site were also approved by the Human Subjects Division at University of Washington; the Human Sciences Research Council Research Ethics Committee in South Africa; the Policy, Planning, Research, Monitoring and Evaluation Committee for the North West Provincial Department of Health; and the CDC's Center for Global Health, Human Research Protection. Procedures for the Mpumalanga site were also approved by the Institutional Review Board at the University of North Carolina at Chapel Hill; the Human Research Ethics Committee of the University of the Witwatersrand, South Africa; and by the Mpumalanga Provincial Health Research Committee.

\subsection{Measures}

Participants in each study responded to a six-item cohesion measure based on the scale developed by Sampson et al. (1997) modified for use following qualitative research and validated by our team (see Table 1 for items) (Lippman et al., 2013; Lippman et al., 2016b). All items had response options of disagree, somewhat agree, and agree. We calculated individual and group cohesion scores using the average of item responses ranging from 0 (Disagree) to 2 (Agree). We used item response modeling (IRM) to assess and summarize the cohesion scale using a one-parameter multinomial (partial credit) model following prior validation (Lippman et al., 2016b; Masters and Wright, 1997). To create a group-level metric of cohesion, we estimated 
Table 1

Characteristics and behaviors of respondents in two South African study sites, 2014

\begin{tabular}{|c|c|c|c|}
\hline & $\begin{array}{c}\text { North West } \\
(\mathrm{N}=43 \text { clusters; } \\
1044 \text { participants })^{\mathrm{a}} \\
\mathrm{N}(\text { Col. \%) }\end{array}$ & $\begin{array}{c}\text { Mpumalanga } \\
\text { (N = 27 clusters; } \\
2057 \text { participants })^{\mathrm{a}} \\
\text { N (Col. \%) }\end{array}$ & $\begin{array}{l}\text { Chi square } \\
\text { test p-value }\end{array}$ \\
\hline \multicolumn{4}{|l|}{ Demographic } \\
\hline \multicolumn{4}{|l|}{ Gender } \\
\hline Men & $401(38.4)$ & $1004(48.8)$ & $\mathrm{p}<0.01$ \\
\hline Women & $643(61.6)$ & $1053(51.2)$ & \\
\hline \multicolumn{4}{|l|}{ Age } \\
\hline $18-29$ & $453(43.4)$ & $1068(51.9)$ & $\mathrm{p}<0.01$ \\
\hline $30-39$ & $344(33.0)$ & $553(26.9)$ & \\
\hline $40-49$ & $247(23.7)$ & $436(21.2)$ & \\
\hline \multicolumn{4}{|l|}{ Education } \\
\hline Primary or less & $241(23.1)$ & $500(24.3)$ & $\mathrm{p}=0.38$ \\
\hline Some secondary & $431(41.3)$ & $915(44.5)$ & \\
\hline $\begin{array}{l}\text { Secondary or } \\
\text { more }\end{array}$ & $372(35.6)$ & $642(31.2)$ & \\
\hline \multicolumn{4}{|l|}{ Marital status } \\
\hline Single & $675(64.7)$ & $1221(59.4)$ & $\mathrm{p}<0.01$ \\
\hline $\begin{array}{l}\text { Married or } \\
\text { cohabitating }\end{array}$ & $321(30.8)$ & $641(31.2)$ & \\
\hline $\begin{array}{l}\text { Separated, } \\
\text { divorced, } \\
\text { widowed }\end{array}$ & $48(4.6)$ & $195(9.5)$ & \\
\hline \multicolumn{4}{|c|}{ Food insecurity past 30 days (going to bed hungry) } \\
\hline No - never & $786(75.3)$ & $1869(90.9)$ & $\mathrm{p}<0.01$ \\
\hline Yes - some days & $258(24.7)$ & $188(9.1)$ & \\
\hline \multicolumn{4}{|l|}{ Behaviors } \\
\hline \multicolumn{4}{|l|}{ Heavy drinking } \\
\hline Men $(\mathrm{N}=401,1004)$ & 179 (44.6) & $232(23.1)$ & $\mathrm{p}<0.01$ \\
\hline Women $(\mathrm{N}=643,1053)$ & $95(14.8)$ & $22(2.1)$ & $\mathrm{p}<0.01$ \\
\hline \multicolumn{4}{|c|}{ HIV testing in past year (among those not previously diagnosed) } \\
\hline $\operatorname{Men}(\mathrm{N}=372,767)$ & $158(42.5)$ & $554(72.2)$ & $\mathrm{p}<0.01$ \\
\hline Women $(\mathrm{N}=555,978)$ & $344(62.0)$ & $819(83.7)$ & $\mathrm{p}<0.01$ \\
\hline \multicolumn{4}{|c|}{ Concurrent sexual partners in past three months (among those sexually active) } \\
\hline Men $(\mathrm{N}=267,686)$ & $42(15.7)$ & $144(21.0)$ & $\mathrm{p}=0.08$ \\
\hline Women $(\mathrm{N}=405,727)$ & $13(3.2)$ & $16(2.2)$ & $\mathrm{p}=0.34$ \\
\hline
\end{tabular}

${ }^{\text {a }}$ Statistics shown represent unweighted data

individual perceived cohesion scores using weighted maximum likelihood estimation (Warm, 1989) from IRM and averaged these within village of residence in Mpumalanga and enumeration area in North West. We also calculated the deviation between individual perception and group cohesion for each respondent in order to assess potential effects at both group and individual levels (Neuhaus and Kalbfleisch, 1998).

We assessed three health outcomes associated with HIV prevention: heavy alcohol use, recent HIV testing, and concurrent sexual partnerships. Heavy alcohol use was measured using the consumption subscale from the World Health Organization's Alcohol Use Disorders Identification Test (AUDIT), an internationally validated screening tool (Babor et al., 2001; Saunders et al., 1993). In accordance with prior studies, we scored the four items on frequency and amount of alcohol consumed from zero to four and classified individuals with four or more total points as heavy drinkers (Bradley et al., 2007; Peltzer, 2006). We defined recent HIV testing as self-reported HIV testing in the past 12 months among those not previously diagnosed with HIV. Concurrent sexual partnership measures were extracted from partner grids, where respondents provided details on their 3 most recent sexual partners, including timing of relationships. Concurrent sexual partnership was defined as at least 1 month of overlapping sexual relations in the past 3 months, among those sexually active in the time frame.

Demographic variables collected in both surveys included age, education (categorized as primary or less, some secondary, secondary or more), union status (single, married/partnered, previously married), and experiencing food insecurity in the past 30 days. We calculated community poverty rates as the percent of respondents reporting food insecurity.

\subsection{Analysis}

We calculated descriptive statistics and tested differences by study region using Chi-square tests or bivariate linear regression adjusted for clustering by group. In order to compare the relationship of cohesion to health outcomes between the two samples, we standardized the Mpumalanga data to the North West sample using weights capturing the inverse probability of being in the North West sample. This was accomplished by modeling North West residence using individual demographics and group poverty in logistic regression models stratified by gender. Final stabilized weights were created by multiplying each weight by the gender-specific probability of being in one's observed location, whether North West or Mpumalanga. This approach extends direct standardization (i.e., by age) to encompass multiple differences in underlying demographics (Hernan et al., 2004). We did not use sampling weights for the purposes of this analysis, as we aimed to make the data sets comparable to each other as opposed to representative of the respective study areas.

We assessed the relationship of both group cohesion (the main exposure of interest) and individual perceived cohesion (to account for individual associations within the groups) with each health outcome separately by gender using multilevel logistic regression. In order to test whether this relationship differed by study site, we included a fixed effect of study site and an interaction term for each cohesion parameter with study site. Because interaction terms were significant for men, women, or both for each outcome (significance of cohesion-study site interaction set at $\mathrm{p}<0.20$ ), we report separate prevalence odds ratios (PORs) for cohesion within each study site.

We conducted a sensitivity analysis using structural equation modeling (SEM) to address the possibility that aggregating individual perception of cohesion to create a group mean would negatively bias regression estimates of contextual effects (Lüdtke et al., 2011). We fit multilevel latent models for each study site and outcome, employing the partial credit IRM model for the initial item model and treating individuals as indicators of the latent group cohesion. All models included the stabilized weights and were adjusted for clustering by group. Analyses were conducted in R 3.1.3 (R Foundation for Statistical Computing) using the Test Analysis Modules package (Kiefer et al., 2015) and Stata 14.0 (StataCorp, College Station, Texas).

\section{Results}

In North West, 43 of 46 selected EAs were successfully enumerated; fieldworkers were not granted access to three farm areas. Of 1527 enumerated dwelling units (DUs), 98.5\% were approached; contact was made at $91.7 \%$, yielding 1146 eligible individuals. A total of 1048 (91.0\% of eligible participants) consented to participate; four individuals were later determined ineligible, resulting in a total sample of 1044. Median cluster size was 25 (IQR: 22-28). In Mpumalanga, the community survey was based on an initial sampling frame of 3456 households across 27 villages, of which 3061 households (88.6\%) were contacted. Eligibility could not be determined in 52 households (refusal prior to screening), in 939 households the selected individual was not eligible (most often due to not meeting residency criteria), and 2070 screened individuals were eligible to participate, with 2057 (99\% of eligible participants) consenting to participate. Median cluster size was 77 (IQR: 75-79).

The combined sample across the two sites included 3101 adults, of which 1696 (54.7\%) were women. As shown in Table 1, compared to the sample in Mpumalanga, respondents in North West were more likely to be female, older, unmarried, and to have experienced food insecurity in the past month. These covariates were all included in the model to calculate inverse weights to standardize the two populations for analytic comparison. Heavy drinking was more common in North West in both men and women, while HIV testing was more commonly reported in Mpumalanga. 
Table 2

Cohesion items and responses in two South African study sites, 2014.

\begin{tabular}{|c|c|c|c|}
\hline \multirow[b]{2}{*}{ Cohesion Scale Items } & \multicolumn{2}{|c|}{ Respondents strongly agreeing N (\%) } & \multirow[b]{2}{*}{ F test of difference between sites } \\
\hline & North West $(\mathrm{N}=973)$ & Mpumalanga $(\mathrm{N}=2057)$ & \\
\hline People in this community are willing to help their neighbors & $457(47.0)$ & $1392(68.0)$ & $40.1, \mathrm{p}<0.01$ \\
\hline This is a close knit community & $371(38.1)$ & $1507(73.4)$ & $91.8, \mathrm{p}<0.01$ \\
\hline People in this community can be trusted & $235(24.2)$ & $1307(63.7)$ & $130.5, \mathrm{p}<0.01$ \\
\hline People in this community get along well with each other & $294(30.2)$ & $1481(72.0)$ & $124.3, \mathrm{p}<0.01$ \\
\hline People in this community share the same values & $139(14.3)$ & $1091(53.1)$ & $77.7, \mathrm{p}<0.01$ \\
\hline People in this community look out for each other & $274(28.2)$ & $1385(67.4)$ & $117.2, \mathrm{p}<0.01$ \\
\hline \multicolumn{4}{|l|}{ Cohesion scale means } \\
\hline Individual perceived cohesion (mean $\pm \mathrm{SD}$ ) & $1.01 \pm 0.55$ & $1.49 \pm 0.60$ & $153.4, \mathrm{p}<0.01$ \\
\hline Group-level cohesion (mean \pm SD) & $1.00 \pm 0.18$ & $1.49 \pm 0.15$ & $155.9, \mathrm{p}<0.01$ \\
\hline
\end{tabular}

An error in skip pattern programming in the survey resulted in 70 male respondents in RSM not being asked about social cohesion. These respondents and one female were excluded from further analysis due to missing cohesion data. They did not differ from observed RSM respondents on health outcomes; we proceeded with a complete case analysis of 973 respondents in RSM. Perceived social cohesion was notably lower in North West than in Mpumalanga, as shown in Table 2. Scale reliability was high, 0.82 across the full sample, using expected a posteriori (EAP) reliability, a statistic analogous to Cronbach's alpha.

The proportion of residents in strong agreement was higher in the Mpumalanga site for all items; individual and group cohesion raw scores averaged 1.0 in the North West site, equivalent to 'somewhat agree' for all items, compared to 1.5 (strong agreement with a minimum of three items) in Agincourt (Fig. 1). Intraclass correlation (ICC) for the cohesion measure was 19.1\% (95\% CI 13.8, 25.5); ICCs did not differ significantly between the two settings.

Table 3 includes results of the multilevel models for each health outcome against group and individual-level cohesion in men (column 2) and women (column 3). Cohesion at each level was quantified using the IRM-based weighted likelihood estimates; group level cohesion ranged from -2.1 to 0.9 on this metric, with units equal to 1 logit, the log odds of endorsing a higher level of agreement on all items.

Consistent with the raw data, in standardized models heavy drinking was significantly more prevalent in men and women in North West, while HIV testing was significantly more common in Mpumalanga. At the group level, cohesion did not demonstrate a significant protective effect on any health outcomes in North West, and in fact was associated with lower reporting of HIV testing among women. Protective effects were not evident at the individual level in the North West site, with the exception of lower prevalence of concurrent

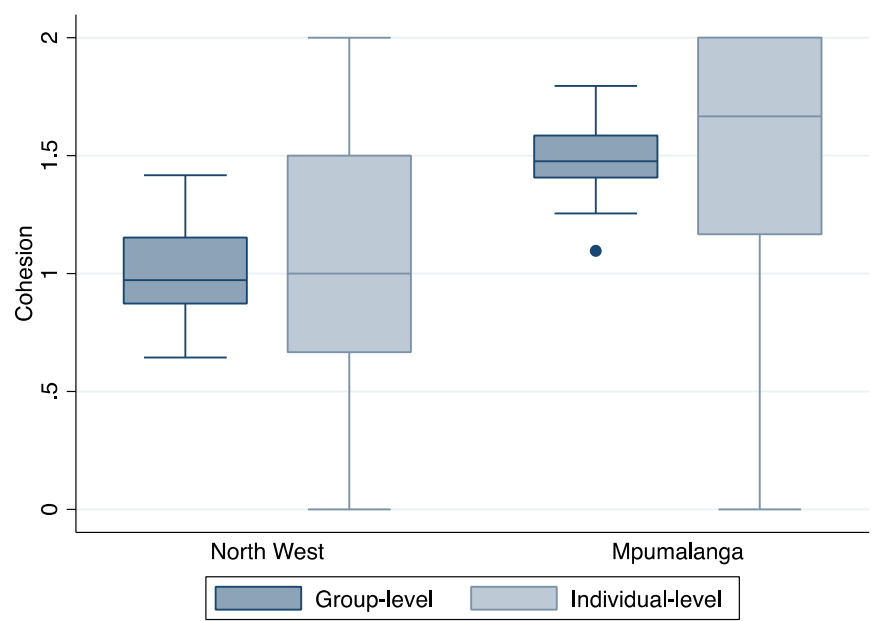

Fig. 1. Median and interquartile range of group and individual-level cohesion at 2 study sites in South Africa ( $\mathrm{N}=70$ groups, $\mathrm{N}=3030$ individuals). sexual partnership among women whose perception of group cohesion was higher than the group mean.

In contrast, several protective associations emerged between group cohesion and health outcomes in Mpumalanga. The odds of men being heavy drinkers were reduced $40 \%$ for each additional unit (logit) of group cohesion (95\% CI $0.25,0.65$ ). Odds of reported HIV testing in the past year were 1.6 and 1.9 times greater in men and women respectively for each unit difference in group cohesion. Group cohesion in Mpumalanga demonstrated signs of being protective against concurrent sexual partnerships among women $(p=0.06)$. There was no evidence of individual effects of perceived cohesion with health outcomes in Agincourt. Sensitivity analyses using latent variable models supported the main analysis (results not shown).

Interaction tests largely underscored the differences in the relationship of cohesion to health outcomes between these sites: interaction between study sites was significant at $\mathrm{p}<0.20$ for heavy drinking in both genders and for HIV testing and concurrent sexual partnerships in women. Fig. 2 illustrates two of the significant interactions with associations most strongly diverging between study sites: group cohesion and heavy drinking among men (2a) and HIV testing among women (2b). A change in group cohesion from -1 to 0 logits results in an estimated increase in heavy drinking prevalence of $17.4 \%$ in North West (not statistically significant), compared to a significant predicted decrease of $19.7 \%$ in Mpumalanga. A unit change in group cohesion results in a predicted $12.0 \%$ decrease in HIV testing prevalence among women in North West vs. a predicted $10.3 \%$ increase in Mpumalanga.

\section{Discussion}

This study measured social cohesion in communities in two rural South African areas, finding broad disparities in levels of perceived group cohesion. We identified potential health benefits of cohesion across three HIV-related health behaviors in Mpumalanga, the region with higher overall evidence of group cohesion. On the contrary, social cohesion was generally not associated with protective behaviors where levels of cohesion were much lower (North West). These results suggest that there may be a minimum threshold or level of group cohesion required to yield positive health effects. To our knowledge, this hypothesis has not previously been put forth; however, non-linear relationships are common in epidemiology and the same may be true for social exposures that influence behaviors only above or below particular thresholds.

We documented an association between community-level social cohesion and decreasing heavy alcohol use among men, which we had observed among men ages 18 - 35 years in a prior survey in Mpumalanga (Leslie et al., 2015). There is some earlier support for this association, with a small number of studies on the context of alcohol use among adolescents in South Africa, noting the relevance of community factors such as neighborhood dereliction in drinking behavior (Brook et al., 2011; Parry et al., 2004). Similarly, Cain et al. (2013) measured perceived collective efficacy in Cape Town as an 
Table 3

Association of perceived cohesion at the group and individual levels with health outcomes in two South African districts, 2014.

\begin{tabular}{|c|c|c|}
\hline & Men POR (95\% CI) & Women POR $(95 \% \mathrm{CI})$ \\
\hline \multicolumn{3}{|l|}{ Heavy drinking } \\
\hline Between-group effects & $\mathrm{N}=1335$ & $\mathrm{~N}=1695$ \\
\hline Study: Mpumalanga relative to North West & $0.15(0.05,0.43)^{c}$ & $0.06(0.03,0.15)^{\mathrm{c}}$ \\
\hline Cohesion in North West & $2.07(0.83,5.14)$ & $1.31(0.78,2.20)$ \\
\hline Cohesion in Mpumalanga & $0.40(0.25,0.65)$ & $0.32(0.07,1.49)$ \\
\hline \multicolumn{3}{|l|}{ Within-group effects } \\
\hline Individual deviation in perceived cohesion, North West & $1.00(0.77,1.31)$ & $0.84(0.67,1.05)$ \\
\hline Individual deviation in perceived cohesion, Mpumalanga & $1.05(0.95,1.15)$ & $0.98(0.77,1.25)$ \\
\hline \multicolumn{3}{|l|}{ HIV testing past 12 months $^{\mathrm{a}}$} \\
\hline Between-group effects & $\mathrm{N}=1079$ & $\mathrm{~N}=1532$ \\
\hline Study: Mpumalanga relative to North West & $2.44(1.14,5.25)$ & $5.81(3.35,10.05)^{c}$ \\
\hline Cohesion in North West & $1.46(0.65,3.30)$ & $0.62(0.42,0.90)$ \\
\hline Cohesion in Mpumalanga & $1.59(1.10,2.30)$ & $1.86(1.01,3.40)$ \\
\hline \multicolumn{3}{|l|}{ Within-group effects } \\
\hline Individual deviation in perceived cohesion, North West & $1.22(0.85,1.74)$ & $1.00(0.76,1.32)$ \\
\hline Individual deviation in perceived cohesion, Mpumalanga & $1.01(0.89,1.15)$ & $1.07(0.96,1.19)$ \\
\hline \multicolumn{3}{|l|}{ Concurrent sexual partners, past 3 months ${ }^{\mathrm{b}}$} \\
\hline Between-group effects & $\mathrm{N}=906$ & $\mathrm{~N}=1132$ \\
\hline Study: Mpumalanga relative to North West & $4.20(0.50,35.10)$ & $0.14(0.01,2.30)^{\mathrm{c}}$ \\
\hline Cohesion in North West & $0.57(0.12,2.62)$ & $2.60(0.30,22.22)$ \\
\hline Cohesion in Mpumalanga & $0.98(0.67,1.42)$ & $0.45(0.19,1.04)$ \\
\hline \multicolumn{3}{|l|}{ Within-group effects } \\
\hline Individual deviation in perceived cohesion, North West & $1.51(0.93,2.49)$ & $0.70(0.49,1.00)$ \\
\hline Individual deviation in perceived cohesion, Mpumalanga & $1.04(0.92,1.18)$ & $0.85(0.61,1.19)$ \\
\hline
\end{tabular}

POR: Prevalence odds ratio.

${ }^{\text {a }}$ Limited to those HIV negative or of unknown status as of 12 months prior.

b Limited to those reporting at least one sexual partner in past 3 months.

${ }^{\mathrm{c}}$ Denotes significant interaction terms. Tests for interaction between study site and cohesion were significant for heavy drinking for men $(\mathrm{B}=-1.63$, $\mathrm{p}<0.01)$ and women $(\mathrm{B}=-$

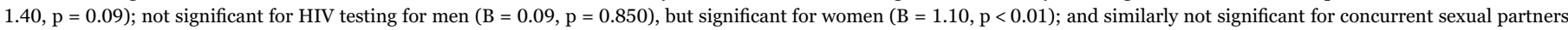
for men $(\mathrm{B}=0.54, \mathrm{p}=0.50)$, but significant for women $(\mathrm{B}=1.76, \mathrm{p}=0.13)$.

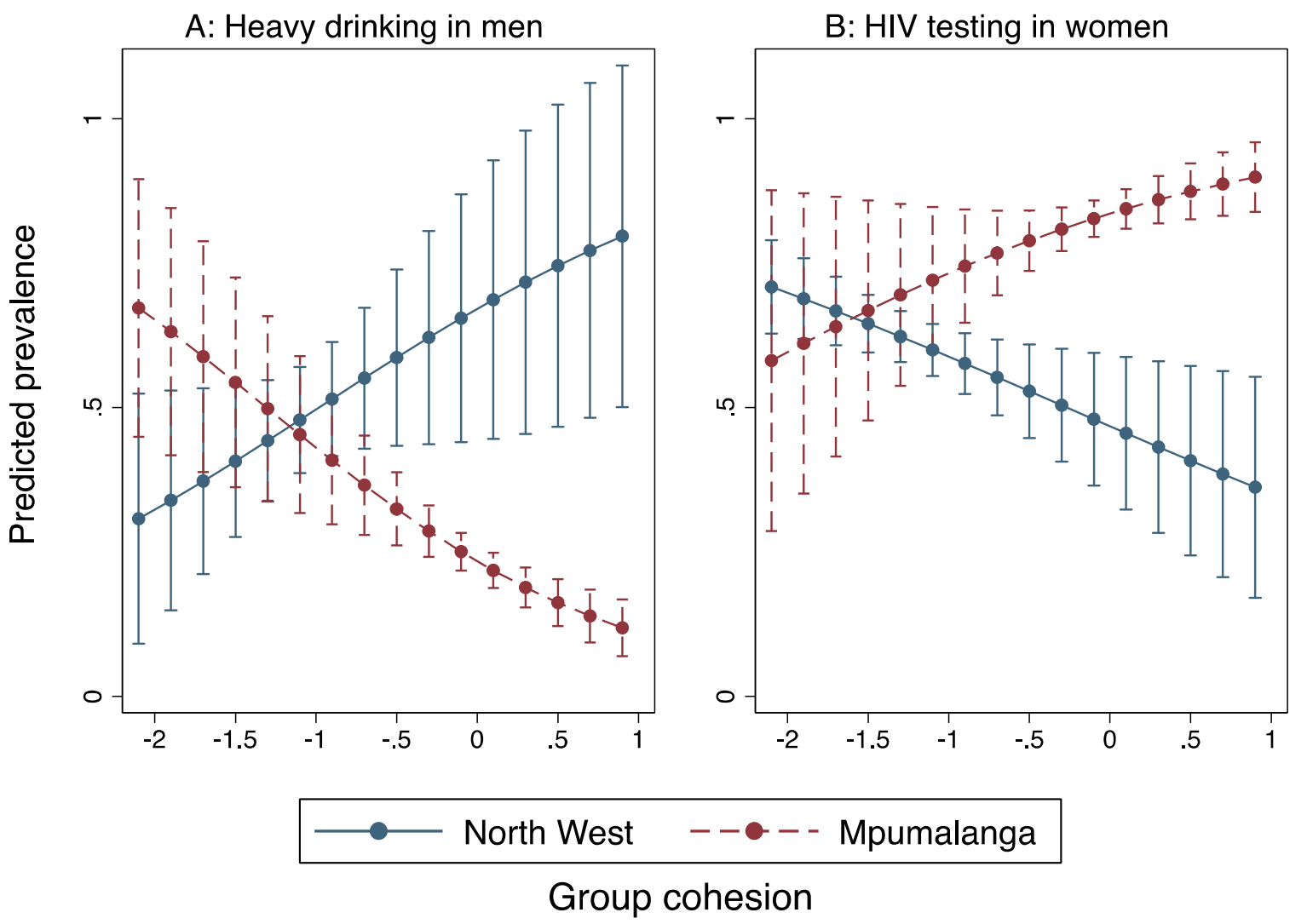

Fig. 2. Predicted prevalence of health outcomes by level of group cohesion in 2 study sites in South Africa. 
individual's belief in his/her community's capacity to prevent HIV, finding it associated with reduced frequency and quantity of alcohol use among men and women.

We also found evidence of an association between community-level social cohesion and increased reported HIV testing for men and women in Mpumalanga. Few previous studies have explored this association in the African context; one study was inconclusive as to whether organizational membership was associated with testing uptake and HIV disclosure (Karim et al., 2008). Finally, we observed that social cohesion could be associated with reductions in partner concurrency among women. Studies in the region suggest a relationship between individual membership in social groups and sexual behaviors, though not all associations were protective (Gregson et al., 2011; Burgard and Lee-Rife, 2009; Pronyk et al., 2008b). The idea that women who perceive their environments to be cohesive or who engage in community groups are less likely to engage in condomless sex has also been established in other low resource settings (Lippman et al., 2010; Kerrigan et al., 2006).

There may be a number of mechanisms by which social cohesion or capital could influence health behaviors, including through diffusion of health information within the cohesive social network or through enforcing healthy normative behaviors, which is facilitated in more cohesive communities with shared values (Kawachi and Berkman, 2000). Additionally, a more cohesive community can bolster individual health and health behaviors by providing an environment that enables people to enact healthy behaviors - both for themselves and for their peers/neighbors (Leslie et al., 2013). In the context of the HIV epidemic in South Africa, Campbell and colleagues have hypothesized that community solidarity can encourage collective dialogue around HIV, a sense of ownership and responsibility to tackle HIV, and the agency to do so (Campbell et al., 2007). Local descriptions and experiences of social cohesion in previous qualitative research in the Mpumalanga site centered largely around shared understandings of instrumental assistance, particularly in times of loss, more so than shared identity. In this context, mutual expectations around shared benefits and burdens of risk behaviors could encourage community members to monitor each other's drinking and partnerships, and encourage health seeking (e.g. HIV testing).

On the contrary - the absence of social cohesion (or the presence of social disorganization), is often linked to unstable community residence, a loss of community social or kinship networks, and ensuing risk behaviors. Historical settlement patterns, political and social structures, current migration, and economic opportunity likely shape community stability and differential levels of cohesion in the study areas. The site in Mpumalanga was initially established during the apartheid government's forced removals programs in the 1940s. However, over time village residents began to strongly identify the village name and boundaries as their 'community,' which was confirmed during qualitative research (Lippman et al., 2013). In this area there is a well-defined structure of village leadership as well as encouragement of local pride through, for example, weekly traditional dances - muchongolo - which are held in four or five villages every weekend. Research in the area has also demonstrated that while circular labor migration is high, residents remain connected to their family homes and their extended families (Clark et al., 2007).

Though much of the North West site is sparsely populated and rural, the area also includes peri-urban communities such as Christiana and Bloemhof, which were established in the late 1800 s by the Transvaal government as part of the diamond mining rush. Now dominated by the cattle and dairy industries, the area remains whiteowned, with the majority of black South Africans settling in informal settlements on the outskirts of the towns, in government-subsidized dwellings, or in village areas run by traditional (tribal) leaders, often located on arid land making subsistence farming difficult. In the agricultural areas, laborers may be co-located primarily for the purpose of work, and not necessarily due to kinship, which forms the basis of much of the mutual assistance noted in the Mpumalanga villages. Many of these local contextual factors likely contribute to differing levels of perceived cohesion between the sites, though further research would be needed to pinpoint the source of disparities.

\subsection{Limitations and strengths}

This study has some limitations, the largest being the crosssectional nature of the data, which limits causal inference. There are some limitations to aggregating data on individual perception: aggregating individual perception can lead to attenuated estimates of these associations where the ICC is low, however we addressed this concern through sensitivity analysis using latent variable models, which showed the same pattern of association. Further, if the functional group or community is not consistent with an individual's perceived community, this approach could result in misclassification. In these merged data, the community clusters were slightly different in the two sites based on pre-defined study sampling units - villages and EAs. While in some cases the units are equivalent (the smaller villages in Mpumalanga are themselves also census EAs), in other cases they may exhibit some differences. However, because the measure performed equivalently between the two aggregation units, with no differential item functioning and with equivalent ICCs, there is no reason to believe that the communities had different understandings of the survey items or that the assignments of individuals to clusters was incomparable. Finally, while we accounted for demographic differences between the sites, there is the possibility of residual confounding.

Among this study's strengths is the assessment of social cohesion and HIV-risk behaviors using a validated community-level metric in South Africa. The majority of work on the subject has been undertaken with individual measures of attributes that have been widely hypothesized to function at the level of the community, but operationalized at the level of the individual (Lippman et al., 2016b). We hypothesized that cohesion works at the community level; however, because there may be multiple pathways, we also explored within group effects by including terms for individual deviations in perceived cohesion. This approach results in a conservative estimate of the group-level associations of social cohesion with outcomes of interest. This is equivalent to a controlled direct effect and isolates the group-level pathway rather than pathways based on changing the composition or perception of individuals.

\subsection{Implications}

Our findings have implications for health programming to address HIV and other health outcomes with community cohesion building initiatives. Our results indicate that increasing group cohesion may produce healthier behaviors; however, some basic level of cohesion and potentially other community contextual elements may need to be present before benefits can be realized. Similar community building efforts in the field of HIV prevention have produced disparate outcomes in different areas of South Africa. For example, the IMAGE trial, which combined a microfinance program with gender and HIV training, demonstrated increases in reported solidarity and group membership in their intervention areas (Pronyk et al., 2008a). However, in Carletonville, in an ethnically diverse area of the North West Province, community building efforts resulted in increased risk for HIV in a context where power structures were not favorable to building cohesive movements (Campbell, 2003). As a result, future research will need to shed light on the eco-social and contextual elements that should be considered and addressed in initiatives aiming to build social cohesion and community solidarity, and on the conceptualization and theoretical frameworks behind collaborative programming to address health and strengthen community contexts (Trickett et al., 2011). The two areas in this study demonstrate that different contexts can lead to differential effects of the benefits of social cohesion on health and health behaviors. 


\section{References}

Babor, T.F., Biddle-Higgins, J.C., Saunders, J.B., Monteiro, M., 2001. AUDIT: the Alcohol Use Disorders IdentificationTest: Guidelines for Use in Primary Health Care Second ed.. World Health Organization, Geneva, Switzerland.

Berkman, L.F., Kawachi, I., 2000. Social Epidemiology. Oxford University Press, New York, NY.

Bradley, K.A., DeBenedetti, A.F., Volk, R.J., Williams, E.C., Frank, D., Kivlahan, D.R., 2007. AUDIT-C as a brief screen for alcohol misuse in primary care. Alcohol.: Clin. Exp. Res. 31, 1208-1217.

Bronfenbrenner, U., 1979. The Ecology of Human Development: Experiments by Nature and Design. Harvard University Press, Cambridge, MA.

Brook, D.W., Rubenstone, E., Zhang, C., Morojele, N.K., Brook, J.S., 2011. Environmental stressors, low well-being, smoking, and alcohol use among South African adolescents. Social. Sci. Med. 72, 1447-1453.

Burgard, S.A., Lee-Rife, S.M., 2009. Community characteristics, sexual initiation, and condom use among young Black South Africans. J. Health Social. Behav. 50, 293-309.

Cain, D., Pitpitan, E.V., Eaton, L., et al., 2013. Collective efficacy and HIV prevention in South African townships. J. Community Health 38, 885-893.

Campbell, C., 2003. 'Letting them Die' Why HIV/AIDS Prevention Programmes Fail Indiana University Press, Bloomington.

Campbell, C., Williams, B., Gilgen, D., 2002. Is social capital a useful conceptual tool for exploring community level influences on HIV infection? An exploratory case study from South Africa. AIDS Care 14, 41-54.

Campbell, C., Foulis, C.A., Maimane, S., Sibiya, Z., 2005. The impact of social environments on the effectiveness of youth HIV prevention: a South African case study. AIDS Care 17, 471-478.

Campbell, C., Nair, Y., Maimane, S., 2007. Building contexts that support effective community responses to HIV/AIDS: a South African case study. Am. J. Community Psychol. 39, 347-363.

Cassel, J., 1976. The contribution of the social environment to host resistance: the Fourth Wade Hampton Frost Lecture. Am. J. Epidemiol. 104, 107-123.

Clark, S.J., Collinson, M.A., Kahn, K., Drullinger, K., Tollman, S.M., 2007. Returning home to die: circular labour migration and mortality in South Africa. Scand. J. Public Health Suppl. 69, 35-44.

Ellen, J.M., Jennings, J.M., Meyers, T., Chung, S.E., Taylor, R., 2004. Perceived social cohesion and prevalence of sexually transmitted diseases. Sex. Transm. Dis. 31, $117-122$.

Fritz, K., Morojele, N., Kalichman, S., 2010. Alcohol: the forgotten drug in HIV/AIDS. Lancet 376, 398-400.

Gregson, S., Mushati, P., Grusin, H., et al., 2011. Social capital and women's reduced vulnerability to HIV infection in rural Zimbabwe. Popul. Dev. Rev. 37, 333-359.

Hernan, M.A., Hernandez-Diaz, S., Robins, J.M., 2004. A structural approach to selection bias. Epidemiology 15, 615-625.

Holtgrave, D.R., Crosby, R.A., 2003. Social capital, poverty, and income inequality as predictors of gonorrhoea, syphilis, chlamydia and AIDS case rates in the United States. Sex. Transm. Infect. 79, 62-64.

Jennings, J.M., Hensel, D.J., Tanner, A.E., Reilly, M.L., Ellen, J.M., 2014. Are social organizational factors independently associated with a current bacterial sexually transmitted infection among urban adolescents and young adults? Social. Sci. Med. $118,52-60$.

Kahn, K., Collinson, M.A., Gomez-Olive, F.X., et al., 2012. Profile: agincourt health and socio-demographic surveillance system. Int. J. Epidemiol. 41, 988-1001.

Kaplan, G.A., Everson, S.A., Lynch, J.W., 2000. The contribution of social and behavioral research to an understanding of the distribution of disease: a multilevel approach. In: Smedley, B.D., Syme, S.L. (Eds.), Promoting Health: Intervention Strategies from Social and Behavioral Research. Washington, D.C.. National Academy Press.

Karim, Q.A., Meyer-Weitz, A., Mboyi, L., et al., 2008. The influence of AIDS stigma and discrimination and social cohesion on HIV testing and willingness to disclose HIV in rural KwaZulu-Natal, South Africa. Glob. Public Health 3, 351-365.

Kawachi, I., Berkman, L., 2000. Social cohesion, social capital, and health. In: Berkman, L.F., Kawachi, I. (Eds.), Social Epidemiology. Oxford University Press, New York, NY.

Kawachi, I., Kennedy, B.P., Lochner, K., Prothrow-Stith, D., 1997. Social capital, income inequality, and mortality. Am. J. Public Health 87, 1491-1498.

Kerrigan, D., Witt, S., Glass, B., Chung, S.E., Ellen, J., 2006. Perceived neighborhood social cohesion and condom use among adolescents vulnerable to HIV/STI. AIDS Behav. 10, 723-729.
Kiefer T., Robitzsch A., Wu M., 2015. Test Analysis Modules. 1.5-2.0 ed. 〈https://CRAN. R-project.org/package=TAM $\rangle$.

Krieger, N., 2001. Theories for social epidemiology in the 21st century: an ecosocial perspective. Int. J. Epidemiol. 30, 668-677.

Leslie, H.H., Ahern, J., Chinaglia, M., Kerrigan, D., Lippman, S.A., 2013. Social participation and drug use in a cohort of Brazilian sex workers. J. Epidemiol. Community Health 67, 491-497.

Leslie, H.H., Ahern, J., Pettifor, A.E., et al., 2015. Collective efficacy, alcohol outlet density, and young men's alcohol use in rural South Africa. Health Place 34, 190-198.

Lippman, S.A., Donini, A., Diaz, J., Chinaglia, M., Reingold, A., Kerrigan, D., 2010. Social-environmental factors and protective sexual behavior among sex workers: the Encontros intervention in Brazil. Am. J. Public Health 100 (Suppl 1), S216-S223.

Lippman, S.A., Maman, S., MacPhail, C., Twine, R., Kahn, K., Pettifor, A., 2013. Conceptualizing community mobilization for HIV prevention: implications for HIV prevention programming in the African context. PLoS One 8 (10), e78208, (Oct 11).

Lippman, S.A., Neilands, T.B., Leslie, H.H., et al., 2016b. Development, validation, and performance of a scale to measure community mobilization. Soc. Sci. Med. 157, $127-137$.

Lippman, S.A., Shade, S.B., El Ayadi, A.M., et al., 2016a. Attrition and Opportunities Along the HIV Care Continuum: Findings From a Population-Based Sample, North West Province, South Africa. J. Acquired Immune Defic. Syndr. 73, 91-99.

Lüdtke, O., Marsh, H.W., Robitzsch, A., Trautwein, U., 2011. A $2 \times 2$ taxonomy of multilevel latent contextual models: accuracy-bias trade-offs in full and partial error correction models. Psychol. Methods 16, 444-467.

Masters, G.N., Wright, B.D., 1997. The partial credit model. In: Linden, W.Jvd, Hambleton, R.K. (Eds.), Handbook of Modern Item Response Theory. Springer, New York, 101-121.

Neuhaus, J.M., Kalbfleisch, J.D., 1998. Between- and within-cluster covariate effects in the analysis of clustered data. Biometrics $54,638-645$.

Parry, C.D., Morojele, N.K., Saban, A., Flisher, A.J., 2004. Brief report: social and neighbourhood correlates of adolescent drunkenness: a pilot study in Cape Town, South Africa. J. Adolesc. 27, 369-374.

Peltzer, K., 2006. Prevalence of alcohol use by rural primary care outpatients in South Africa. Psychol. Rep. 99, 176-178.

Poundstone, K.E., Strathdee, S.A., Celentano, D.D., 2004. The social epidemiology of human immunodeficiency virus/acquired immunodeficiency syndrome. Epidemiol. Rev. 26, 22-35.

Pronyk, P.M., Hargreaves, J.R., Kim, J.C., et al., 2006. Effect of a structural intervention for the prevention of intimate-partner violence and HIV in rural South Africa: a cluster randomised trial. Lancet 368, 1973-1983.

Pronyk, P.M., Harpham, T., Busza, J., et al., 2008a. Can social capital be intentionally generated? A randomized trial from rural South Africa. Soc. Sci. Med. 67, 1559-1570.

Pronyk, P.M., Harpham, T., Morison, L.A., et al., 2008b. Is social capital associated with HIV risk in rural South Africa? Social. Sci. Med. 66, 1999-2010.

Sampson, R.J., 2003. The neighborhood context of well-being. Perspect. Biol. Med. 46, S53-S64.

Sampson, R.J., Raudenbush, S.W., Earls, F., 1997. Neighborhoods and violent crime: a multilevel study of collective efficacy. Science 277, 918-924.

Saunders, J.B., Aasland, O.G., Babor, T.F., De La Fuente, J.R., Grant, M., 1993. Development of the Alcohol Use Disorders Identification Test (AUDIT): WHO Collaborative Project on Early Detection of Persons with Harmful Alcohol Consumption-II. Addiction 88, 791-804.

Shisana, O., Rehle, T., Simbayi, L.C., Zuma, K., Jooste, S., Zungu, N., Labadarios, D., Onoya, D., et al., 2014. South African National HIV Prevalence, Incidence and Behaviour Survey, 2012. HSRC Press, Cape Town.

Trickett, E.J., Beehler, S., Deutsch, C., et al., 2011. Advancing the science of communitylevel interventions. Am. J. Public Health 101, 1410-1419.

Underwood, C., Hendrickson, Z., Van Lith, L.M., Lengwe Kunda, J.E., Mallalieu, E.C., 2014. Role of community-level factors across the treatment cascade: a critical review. J. Acquir Immune Defic. Syndr. 66 (Suppl 3), S311-S318.

Warm, T.A., 1989. Weighted likelihood estimation of ability in item response theory. Psychometrika 54, 427-450.

Youngblade, L.M., Curry, L.A., Novak, M., Vogel, B., Shenkman, E.A., 2006. The impact of community risks and resources on adolescent risky behavior and health care expenditures. J. Adolesc. Health.: Off. Publ. Soc. Adolesc. Med. 38, 486-494. 